\title{
Analisis Kinerja Dalam Pendukung Keputusan Pemilihan Vendor Pada Unit Bisnis Sistem Transportasi Di PT LEN Industri (Persero) Menggunakan Metode Profile Matching
}

\author{
Hilman Setiadi'), Maulana Malik Rizqian'2), Ali Mohamad Rezza ${ }^{3)}$ \\ ${ }_{1}$ Logistik Bisnis, Politeknik Pos Indonesia \\ email: hilmansetiadi@poltekpos.ac.id \\ ${ }_{2}$ Logistik Bisnis, Politeknik Pos Indonesia \\ email: maulanamr.mmr@gmail.com \\ ${ }_{3}$ Logistik Bisnis, Politeknik Pos Indonesia \\ email: alimohamad.rezza@poltekpos.ac.id \\ Abstrak
}

\begin{abstract}
Vendor merupakan salah satu mitra bisnis strategis bagi perusaan. Peranannya sangat penting guna menjamin ketersediaan material yang dibutuhkan dalam pengerjaan suatu project. Dalam implementasi pengadaan material,l ada kalanya vendor tidak bisa menjaga komitmennya sehingga berdampak pada project yang sedang berjalan. Terganggunya project dapat berdampak pada penganggaran biaya yang telah direncanakan. Lebih jauh, kondisi seperti ini akan berpengaruh terhadap proses produksi yang telah direnakan. Menghadapi permasalahan tersebut, perlu dilakukan penilaian agar mampu memenuhi kebutuhan project secara konsisten. Pada penelitian ini digunakan Metode Profile Matching untuk menentukan vendor mana yang memiliki peringkat yang terbaik. Pengambilan keputusan akan dilakukan dengan membandingkan gap antara nilai alternatif dan kriteria yang diinginkan perusahaan. Berdasarkan hasil penelitian terhadap ketiga vendor yang maka vendor Supreme menempati peringkat pertama dengan nilai hasil akhir 5,18, disusul dengan vendor Leoni di peringkat kedua dengan nilai hasil akhir 5,1 dan vendor JLAPP menempati peringkat ketiga dengan nilai hasil akhir 4,97. Hasil pemeringkatan ini dijadikan sebagai masukkan bagi perusahaan dalam menentukan mitra utama dan bagi vendor sebagai evaluasi guna meningkatkan kinerjanya sehingga dapat menjadi pilihan utama bagi perusahaan.
\end{abstract}

Kata Kunci: Profile Matching, pemeringkatan, Kinerja, Vendor

\section{PENDAHULUAN}

Vendor merupakan salah satu jenis mitra bisnis strategis yang memegang peranan sangat penting dalam menjamin ketersediaan barang/material yang dibutuhkan dalam project yang sedang berlangsung. Sebuah perusahaan yang sehat dan efisien tidak akan banyak berarti apabila vendornya tidak mampu untuk memberikan material/ barang yang berkualitas dan tidak mampu memenuhi pengiriman yang tepat waktu. Apabila vendor tidak dapat menjaga komitmennya, hal ini akan berdampak terhadap project yang sedang berjalan, sehingga project dapat terganggu dan dapat berdampak juga pada anggaran biaya yang telah direncanakan. Dalam hal ini telah terjadi penurunan komitmen vendor terhadap perusahaan, dimana telah ditemukan pihak vendor tidak mampu mengirimkan material/barang secara tepatwaktu. Pemilihan vendorperlu dilakukan untuk mendapatkan vendor yang benar-benar mampu memenuhi kebutuhan project secara konsisten.

Pemilihan vendor sebagai mitra bisnis merupakan sebuah isu penting bagi pimpinan perusahaan (Arini, 2015; Nisa dan
Sutinah, 2018). Kurniawan et al, (2017) permasalahan multi kriteria dimana setiap kriteria yang digunakan mempunyai kepentingan yang berbeda dan informasi mengenai hal tersebut tidak diketahui secara tepat.

Penerapan metode Profile Matching dilakukan (Nisa dan Sutinah, 2018) dalam menentukan vendor Maintaenance server dan Jaringan, (Sutinah, 2017) dalam menentukansalesman terbaik yang akan dipromosikan menjadi sales manajer, (Permana, 2016) dalam penentuan Supplier Suku Cadang Mobil dengan menggunakan empat kriteria yaitu harga, kualitas barang, ketepatan waktu pengadaan barang dan keramahan. Sementra (Mufid, 2014) untuk menentukan perangkat lunak sistem pendukung keputusan untuk penilaian proposal PNPM-MPd yang dapat menentukan ranking nilai dari yang tertinggi sampai terendah sementara dalam penelitian ini menentukan vendor pada unit bisnis Sistem Transportasi di PT Len Industri (Persero) Penelitian ini bertujuan untuk mengetahui berapa nilai total yang diperoleh dari masing-masing vendor dan bagaimana hasil akhir yang diperoleh dari masing-masing vendor serta vendor mana 
yang terbaik dari hasil pemeringkatan beerdasarkan bobot prioritas dari yang tertinggi hingga yang terendah

\section{METODE PENELITIAN}

Penelitian ini dilakukan di PT Len Industri (Persero) khususnya di Unit Bisnis Sistem Transportasi, untuk menilai dan mengukur kinerja vendor yang terbaik sehingga dapat digunakan sebagai pendukung keputusan dalam pemilihan vendor yang akan dilakukan kerjasama nantinya. Adapun asumsi yang digunakan yaitu responden tidak ada konflik kepentingan terhadap vendor yang diseleksi dan responden dapat mengetahui kriteria dari masing-masing vendor serta dapat memberikan penilaian kepada vendor berdasarkan kriteria yang ditetapkan denan baik.

Penggunaan metode profil matching dilakukan guna mendukung keputusan terhadap permasalahan yang dihadapi dengan membandingkan gap antara nilai alternatif dengan kriteria yang diinginkan perusahaan. Dengan metode ini maka dapat ditentukan peringkat vendor mana yang paling baik untuk dijadikan mitra kerja sama.Pada penelitian ini, digunakan beberapa teknik pengumpulan data, yaitu:

\subsection{Data Primer}

a. Wawancara, yaitu cara mengumpulkan data dengan cara melakukan percakapan secara langsung yang dilakukan antara pewawancara yang mewawancara dan narasumber sebagai sumber dari informasi. Pada penelitian ini, Penulis melakukan wawancara kepada karyawan PT Len Industri (Persero) yang berhubungan dengan permasalahan yang terjadi khususnya di Unit Bisnis Sistem Transportasi (UB Sistrans).

b. Kuisioner, yaitu mengumpulkan data dengan menyebarkan lembar penilaian yang berkaitan dengan penelitian yang akan diteliti. Responden dari kuisioner ini adalah pihak yang memiliki pengalaman dan ahli dibidangnya.

\subsection{Data Sekunder}

Studi literature, yaitu melengkapi data melalui literature dari buku pustaka maupun media lainnya.Langkah-langkah pemecahan masalah dalam metode profile matching adalah sebagai berikut:

5) Perhitungan core factor dan secondary factor
1) Pengumpulan Data

Pengumpulan data dibutuhkan untuk pengolahan data penelitian yang akan diteliti. Pengumpulan data diperoleh dari lembar penilaian atau kuisioner dan wawancara.

2) Penyelesaian Masalah dengan Profile Matching Penyelesaian masalah dengan menggunakan metode Profile Matching merupakan sebuah metode penyelesaian masalah yang berhubungan dengan sistem pendukung keputusan dengan membandingkan gap antara nilai profil atribut, yaitu penilaian kinerja vendor dan nilai profil standar, yaitu nilai standar yang diinginkan oleh perusahaan terhadap kriteria yang telah ditentukan.

3) Pemetaan Gap

Proses perhitungan pemetaan gap masing-masing vendor akan dinilai langsung oleh pihak yang memilliki pengetahuan di bidang terkait.

Gap = Nilai Vendor - Nilai Standar (Minimum)

4) Melakukan Pembobotan

Pembobotan dilakukan setelah pemetaan gap, setelah nilai gap diperoleh, maka proses selanjunya akan dilakukan konversi ke dalam bobot nilai sesuai dengan hasil gap yang telah diperoleh

Tabel 1 Pembobotan Nilai Gap

\begin{tabular}{|c|c|c|l|}
\hline No & Selisih & $\begin{array}{c}\text { Bobot } \\
\text { Nilai }\end{array}$ & \multicolumn{1}{|c|}{ Keterangan } \\
\hline 1 & 0 & 6 & $\begin{array}{l}\text { Tidak ada selisih (Kompetensi sesuai } \\
\text { dengan yang dibutuhkan }\end{array}$ \\
\hline 2 & 1 & 5,5 & Kompetensi individu kelebihan 1 tingkat \\
\hline 3 & $\cdot 1$ & 5 & Kompetensi individu kekurangan 1 tingkat \\
\hline 4 & 2 & 4,5 & Kompetensi individu kelebihan 2 tingkat \\
\hline 5 & -2 & 4 & Kompetensi individu kekurangan 2 tingkat \\
\hline 6 & 3 & 3,5 & Kompetensi individu kelebihan 3 tingkat \\
\hline 7 & -3 & 3 & Kompetensi individu kekurangan 3 tingkat \\
\hline 8 & 4 & 2,5 & Kompetensi individu kelebihan 4 tingkat \\
\hline 9 & -4 & 2 & Kompetensi individu kekurangan 4 tingkat \\
\hline 10 & 5 & 1,5 & Kompetensi individu kelebihan 5 tingkat \\
\hline 11 & -5 & 1 & Kompetensi individu kekurangan 5 tingkat \\
\hline
\end{tabular}

Proses perhitungan core factor dan secondary factor dilakukan dengan cara menentukan terlebih dahulu kriteria-kriteria. Kriteria tersebut dipisah menjadi kriteria yang akan dijadikan core factor dan secondary factor. Kriteria yang dijadikan core factor dan secondary factor diperoleh berdasarkan hasil dari wawancara dan pengajuan yang dilakukan oleh Penulis kepada karyawan yang ahli dan berpengalaman di bidangnya. Perhitungan core factor dapat ditunjukkan pada rumus di bawah ini: 


$$
\mathrm{NCF}=\frac{\sum N C}{\sum I C}
$$

Keterangan:

$\mathrm{NCF}$ : Nilai rata-rata core factor

$\mathrm{NC}$ : Jumlah total nilai core factor

IC : Jumlah Item core factor

Perhitungan secondary factor dapat ditunjukkan pada rumus di bawah ini:

$$
\mathrm{NSF}=\frac{\sum N S}{\sum I S}
$$

Keterangan:

NSF: Nilai rata-rata secondary factor

NS : Jumlah total nilai secondary factor

IS : Jumlah Item secondary factor

\section{6) Perhitungan Nilai Total}

Perhitungan nilai total diperoleh dari pembagian dari persentase dari nilai core factor dan secondary factor.

Presentase core factor sebesar $60 \%$ dan presentase secondary factor sebesar $40 \%$.

$\mathrm{NT}=(60 \% \times \mathrm{NCF})+(40 \% \times \mathrm{NSF})$

Keterangan:

NT: Nilai Total

NCF: Nilai core factor

NSF: Nilai secondary factor

7) Melakukan Perangkingan

Setelah nilai total ditemukan, maka dilakukan sistem perankingan, di mana nilai tertinggi akan berada diurutan teratas dan nilai terendah akan berada diurutan terbawah

\section{8) Penentuan Perhitungan Peringkat}

Hasil akhir dari proses ini adalah peringkat. Penentuan peringkat adalah pemeringkatan berdasarkan penilaian total keseluruhan dari faktor utama (core factor) dan faktor tambahan (secondary factor).

\section{Ranking $(\mathrm{HA})=(\mathrm{x}) \% \mathrm{Nk}+(\mathrm{x}) \% \mathrm{Nh}+(\mathrm{x}) \% . \mathrm{N}$}

Keterangan:

HA : Ranking

Nk : Nilai Kriteria Kualitas

\author{
Nh : Nilai Kriteria Harga \\ $\mathrm{Nl}$ : Nilai Kriteria Lead Time \\ (x)\%: Nilai persentase yang diinputkan
}

\section{HASIL DAN PEMBAHASAN}

Pada bagian point ini akan membahas mengenai hasil dari penelitian dari data yang telah diolah. Adapaun hasilnya sebagai berikut:

\subsection{Penentuan Kriteria Penilaian}

Proses penetuan kriteria menjadi tolak ukur dalam pemilihan dan penilaian terhadap vendor sesuai dengan Metode yang digunakan. Pada proses ini, cara yang dilakukan dalam menentukan kriteria penilaian dilakukan dengan cara melakukan wawancara disertai dengan melakukan pengajuan kepada pihak yang menjadi narasumber. Pada Tabel 2 dapat dilihat kriteria-kriteria penilaian.

\section{Tabel 2 Kriteria-kriteria Penilaian}

\begin{tabular}{|l|l|l|}
\hline No & \multicolumn{1}{|c|}{ Kriteria } & \multicolumn{1}{c|}{ Subkriteria } \\
\hline 1 & Kualitas & - Kesesuaian dengan Spesifikasi \\
& & - Daya Tanggap (Respon Vendor) \\
& & $\begin{array}{l}\text { - Jaminan } \\
\text { - Pengalaman Perusahaan (Reputasi) }\end{array}$ \\
\hline 2 & Harga & $\begin{array}{l}\text { - Harga Yang ditawarkan Vendor } \\
\text { - Cara Pembayaran }\end{array}$ \\
& & - Potongan Harga \\
\hline 3 & Lead Time & - Waktu Tunggu \\
\hline
\end{tabular}

Pada kriteria-kriteria penilaian diatas, subkriteria dikelompokan menjadi core factor dan secondary factor. Pada kriteria kualitas yang menjadi core factor adalah subkriteria kesesuaian dengan spesifikasi dan jaminan. Sedangkan yang menjadi secondary factor adalah subkriteria daya tanggap perusahaan dan pengalaman perusahaan. Pada kriteria harga yang menjadi core factor adalah subkriteria harga yang ditawarkan vendor dan cara pembayaran. Sedangakan yang menjadi secondary factor adalah subkriteria potongan harga. Pada kriteria lead time hanya terdapat core factor saja yaitu subkriteria waktu tunggu

\subsection{Pembobotan Nilai core factor dan secondary factor} Pada tahap ini, ada beberapa langkah yang harus dilakukan sebelum melakukan pembobotan dengan melakukan pemetaan gap yang lebih rinci sebagaimana dapat dilihat pada tabel 3, 4 dann 5 .

1. Pemetaan Gap 
Tabel 3 Pemetaan Gap Kriteria Kualitas

\begin{tabular}{|c|c|c|c|c|c|c|}
\hline \multirow[t]{2}{*}{ No } & \multirow{2}{*}{$\begin{array}{c}\text { Nama } \\
\text { Vendor }\end{array}$} & \multicolumn{4}{|c|}{ Kriteria Kualitas } & \multirow[t]{2}{*}{ Ket. } \\
\hline & & (A) & (B) & (C) & (D) & \\
\hline 1 & Supreme & 4 & 4 & 4 & 4 & \\
\hline 2 & JLAPP & 4 & 4 & 4 & 4 & \\
\hline 3 & Leoni & 4 & 4 & 4 & 4 & \\
\hline \multicolumn{2}{|c|}{ Nilai Standar } & 4 & 4 & 4 & 4 & \\
\hline \multicolumn{7}{|c|}{ Caranya : JLAPP $=4-3=1$ maka nilai gap dari subkriteria " $\mathrm{A} "=1$} \\
\hline 1 & Supreme & 0 & 0 & 0 & 0 & \multirow{3}{*}{ Gap } \\
\hline 2 & JLAPP & 0 & 0 & 0 & 0 & \\
\hline 3 & Leoni & 0 & 0 & 0 & 0 & \\
\hline
\end{tabular}

Tabel 4 Pemetaan Gap Kriteria Harga

\begin{tabular}{|c|c|c|c|c|c|}
\hline \multirow[t]{2}{*}{ No } & \multirow{2}{*}{$\begin{array}{c}\text { Nama } \\
\text { Vendor }\end{array}$} & \multicolumn{3}{|c|}{ Kriteria Harga } & \multirow[t]{2}{*}{ Ket. } \\
\hline & & (E) & (F) & (G) & \\
\hline 1 & Supreme & 4 & 4 & 4 & \\
\hline 2 & JLAPP & 3 & 4 & 3 & \\
\hline 3 & Leoni & 3 & 3 & 3 & \\
\hline \multicolumn{2}{|c|}{ Nilai Standar } & 4 & 3 & 3 & \\
\hline \multicolumn{6}{|c|}{ Caranya : JLAPP $=4-3=1$ maka nilai gap dari subkriteria "E" $=1$} \\
\hline 1 & Supreme & 0 & 1 & 1 & \multirow{3}{*}{ Gap } \\
\hline 2 & JLAPP & -1 & 1 & 0 & \\
\hline 3 & Leoni & -1 & 0 & 0 & \\
\hline
\end{tabular}

Tabel 5 Pemetaan Gap Kriteria Lead Time

\begin{tabular}{|c|c|c|c|}
\hline No & \multirow{2}{*}{$\begin{array}{c}\text { Nama } \\
\text { Vendor }\end{array}$} & Kriteria Lead Time & \multirow{2}{*}{ Ket. } \\
\cline { 3 - 3 } & Supreme & 4 & \\
\hline 1 & & 3 & \\
\hline 2 & JLAPP & 3 & \\
\hline 3 & Leoni & 4 & \\
\hline
\end{tabular}

Tabel 5 Pemetaan Gap Kriteria Lead Time (Lanjutan)

\begin{tabular}{|c|c|c|c|}
\hline \multirow[t]{2}{*}{ No } & Nama & Kriteria Lead Time & \multirow[t]{2}{*}{ Ket. } \\
\hline & Vendor & (H) & \\
\hline \multicolumn{4}{|c|}{ Caranya : JLAPP $=4-3=1$ maka nilai gap dari subkriteria " $\mathrm{H}$ " $=1$} \\
\hline 1 & Supreme & 0 & \multirow{2}{*}{ Gap } \\
\hline 2 & JLAPP & -1 & \\
\hline 3 & Leoni & -1 & \\
\hline
\end{tabular}

2. Pembobotan

Setiap gap yang diperoleh, nilainya akan dikonversikan kedalam bobot nilai sesuai hasil dari nilai gap yang diperoleh setiap vendor. Hasil pembobotan dapat dilihat pada tabel 6,7 dan 8 .

Tabel 6 Hasil Pemetaan Gap Kompetensi dan Hasil Pembobotan Nilai Gap Vendor Supreme

\begin{tabular}{|c|c|c|l|}
\hline $\begin{array}{c}\text { Kriteria- } \\
\text { kriteria }\end{array}$ & $\begin{array}{c}\text { Nilai } \\
\text { Gap }\end{array}$ & $\begin{array}{c}\text { Hasil } \\
\text { Bobot } \\
\text { Nilai }\end{array}$ & \multicolumn{1}{|c|}{ Keterangan } \\
\hline Kualitas & & & \\
\hline A & 0 & 6 & Nilai gapnya 0 bobotnya 6 \\
\hline B & 0 & 6 & Nilai gapnya 0 bobotnya 6 \\
\hline C & 0 & 6 & Nilai gapnya 0 bobotnya 6 \\
\hline D & 0 & 6 & Nilai gapnya 0 bobotnya 6 \\
\hline Harga & & & \\
\hline E & 0 & 6 & Nilai gapnya 0 bobotnya 6 \\
\hline F & 1 & 5,5 & Nilai gapnya 1 bobotnya 5,5 \\
\hline G & 1 & 5,5 & Nilai gapnya 1 bobotnya 5,5 \\
\hline Lead Time & & & \\
\hline H & 0 & 6 & Nilai gapnya 0 bobotnya 6 \\
\hline
\end{tabular}

Tabel 7 Hasil Pemetaan Gap kompetensi dan Hasil Pembobotan Nilai Gap Vendor JLAPP

\begin{tabular}{|c|c|c|l|}
\hline $\begin{array}{c}\text { Kriteria- } \\
\text { kriteria }\end{array}$ & $\begin{array}{c}\text { Nilai } \\
\text { Gap }\end{array}$ & $\begin{array}{c}\text { Hasil Bobot } \\
\text { Nilai }\end{array}$ & \multicolumn{1}{|c|}{ Keterangan } \\
\hline Kualitas & & & \\
\hline A & 0 & 6 & Nilai gapnya 0 bobotnya 6 \\
\hline B & 0 & 6 & Nilai gapnya 0 bobotnya 6 \\
\hline C & 0 & 6 & Nilai gapnya 0 bobotnya 6 \\
\hline D & 0 & 6 & Nilai gapnya 0 bobotnya 6 \\
\hline
\end{tabular}


Tabel 7 Hasil Pemetaan Gap kompetensi dan Hasil Pembobotan Nilai Gap Vendor JLAPP (Lanjutan)

\begin{tabular}{|c|c|c|l|}
\hline Harga & & & \\
\hline E & -1 & 5 & Nilai gapnya -1 bobotnya 5 \\
\hline F & 1 & 5,5 & Nilai gapnya 0 bobotnya 5,5 \\
\hline G & 0 & 6 & Nilai gapnya 0 bobotnya 6 \\
\hline Lead Time & & & \\
\hline H & -1 & 5 & Nilai gapnya -1 bobotnya 5 \\
\hline
\end{tabular}

Tabel 8 Hasil Pemetaan Gap Kompetensi dan Hasil Pembobotan Nilai Gap Vendor Leoni

\begin{tabular}{|c|c|c|c|}
\hline $\begin{array}{c}\text { Kriteria- } \\
\text { kriteria }\end{array}$ & $\begin{array}{l}\text { Nilai } \\
\text { Gap }\end{array}$ & $\begin{array}{c}\text { Hasil Bobot } \\
\text { Nilai }\end{array}$ & Keterangan \\
\hline \multicolumn{4}{|l|}{ Kualitas } \\
\hline $\mathbf{A}$ & 0 & 6 & Nilai gapnya 0 bobotnya 6 \\
\hline B & 0 & 6 & Nilai gapnya 0 bobotnya 6 \\
\hline $\mathbf{C}$ & 0 & 6 & Nilai gapnya 0 bobotnya 6 \\
\hline D & 0 & 6 & Nilai gapnya 0 bobotnya 6 \\
\hline \multicolumn{4}{|l|}{ Harga } \\
\hline $\mathbf{E}$ & -1 & 5 & Nilai gapnya -1 bobotnya 5 \\
\hline $\mathbf{F}$ & 0 & 6 & Nilai gapnya 0 bobotnya 6 \\
\hline $\mathbf{G}$ & 0 & 6 & Nilai gapnya 0 bobotnya 6 \\
\hline \multicolumn{4}{|l|}{ Lead Time } \\
\hline $\mathbf{H}$ & -1 & 5 & Nilai gapnya -1 bobotnya 5 \\
\hline
\end{tabular}

\subsection{Perhitungan Nilai Total Vendor}

Sebelum dilakukan perhitungan nilai total vendor, ada langkah-langkah yang harus dilakukan. Adapun langkah- langkahnya adalah:

1. Perhitungan core factor dan secondary factor Kriteria core factor adalah kriteria yang paling utama untuk menentukan sebuah keputusan. Sedangkan kriteria secondary factor adalah kriteria untuk mendukung core factor. Hasil perhitungan dapat dilihat pada tabel 9, 10 dan 11 .

Tabel 9 Perhitungan Core Factor dan Secondary Factor Kriteria Kualitas

\begin{tabular}{|c|c|c|c|c|c|c|c|}
\hline \multirow[t]{2}{*}{ No } & \multirow[t]{2}{*}{ Nama } & \multicolumn{4}{|c|}{$\begin{array}{c}\text { Kriteria Sikap } \\
\text { Kualitas }\end{array}$} & \multirow{2}{*}{$\begin{array}{l}\text { Core Factor } \\
\mathrm{NCF}=\frac{\sum N C}{\sum I C}\end{array}$} & \multirow{2}{*}{$\begin{array}{c}\text { Secondary } \\
\text { Factor } \\
\mathrm{NSF}=\frac{\sum N S}{\sum I S}\end{array}$} \\
\hline & & $\mathbf{A}$ & B & C & D & & \\
\hline 1 & Supreme & 6 & 6 & 6 & 6 & $\begin{array}{l}\mathrm{NCF}=\frac{6+6}{2} \\
=6\end{array}$ & $\mathrm{NSF}=\frac{6+6}{2}=6$ \\
\hline
\end{tabular}

Tabel 9 Perhitungan Core Factor dan Secondary Factor Kriteria Kualitas (Lanjutan)

\begin{tabular}{|l|l|l|l|l|l|l|l|}
\hline 2 & JLAPP & 6 & 6 & 6 & 6 & $\begin{array}{l}\text { NCF }=\frac{6+6}{2} \\
=6\end{array}$ & NSF $=\frac{6+6}{2}=6$ \\
\hline 3 & Leonio & 6 & 6 & 6 & 6 & $\begin{array}{l}\text { NCF }=\frac{6+6}{2} \\
=6\end{array}$ & NSF $=\frac{6+6}{2}=6$ \\
\hline
\end{tabular}

Tabel 10 Perhitungan Core Factor dan Secondary Factor Kriteria Harga

\begin{tabular}{|c|c|c|c|c|c|c|}
\hline \multirow{2}{*}{ No } & \multirow{2}{*}{ Nama } & \multicolumn{3}{|c|}{ Kriteria Harga } & \multirow{2}{*}{$\begin{array}{l}\text { Core Factor } \\
\mathrm{NCF}=\frac{\sum N C}{\sum I C}\end{array}$} & \multirow{2}{*}{$\begin{array}{c}\text { Secondary } \\
\text { Factor } \\
\mathrm{NSF}=\frac{\sum N S}{\sum I S}\end{array}$} \\
\hline & & $\mathbf{E}$ & $\mathbf{F}$ & G & & \\
\hline 1 & Supreme & 6 & 5,5 & 5,5 & $\begin{array}{l}N C F=\frac{6+5,5}{2} \\
=5,75\end{array}$ & $N S F=\frac{5,5}{1}=5,5$ \\
\hline 2 & JLAPP & 5 & 5,5 & 6 & $\begin{array}{l}\mathrm{NCF}=\frac{5+5,5}{2} \\
=5,25\end{array}$ & $N S F=\frac{6}{1}=6$ \\
\hline 3 & Leoni & 5 & 6 & 6 & $\begin{array}{l}\mathrm{NCF}=\frac{5+6}{2} \\
=5,5\end{array}$ & $N S F=\frac{6}{1}=6$ \\
\hline
\end{tabular}

Tabel 11 Perhitungan Core Factor dan Secondary Factor Kriteria Lead Time

\begin{tabular}{|c|c|c|c|c|}
\hline \multirow[t]{2}{*}{ No } & \multirow[t]{2}{*}{ Nama } & $\begin{array}{c}\text { Kriteria } \\
\text { Lead Time }\end{array}$ & \multirow{2}{*}{$\begin{array}{l}\text { Core Factor } \\
\mathrm{NCF}=\frac{\sum N C}{\sum I C}\end{array}$} & \multirow{2}{*}{$\begin{array}{c}\text { Secondary } \\
\text { Factor } \\
\mathrm{NSF}=\frac{\sum N S}{\sum I S}\end{array}$} \\
\hline & & H & & \\
\hline 1 & Supreme & 6 & $N C F=\frac{6}{1}=6$ & - \\
\hline 2 & JLAPP & 5 & $\mathrm{NCF}=\frac{5}{1}=5$ & - \\
\hline 3 & Leoni & 5 & $\mathrm{NCF}=\frac{5}{1}=5$ & - \\
\hline
\end{tabular}

2. Perhitungan Nilai Total

Setelah dilakukan perhitungan core factor dan secondary factor, maka tahap berikutnya adalah perhitungan nilai total berdasarkan persentase dari core factor dan secondary factor yang diperkirakan berpengaruh terhadap kinerja tiap-tiap vendor. Presentase core factor sebesar $60 \%$ dan secondary factor sebesar $40 \%$. Nilai total tiap-tiap vendor dapat dilihat pada tabel 12, 13, dan 14 . 
Tabel 12 Nilai Total Kriteria Kualitas

\begin{tabular}{|l|l|l|l|l|}
\hline No & Nama & NCF & NSF & NT \\
\hline 1 & Supreme & 6 & 6 & 6 \\
\hline 2 & JLAPP & 6 & 6 & 6 \\
\hline 3 & Leoni & 6 & 6 & 6 \\
\hline
\end{tabular}

Tabel 13 Nilai Total Kriteria Harga

\begin{tabular}{|l|l|l|l|l|}
\hline No & Nama & NCF & NSF & NT \\
\hline 1 & Supreme & 5,75 & 5,5 & 5,65 \\
\hline 2 & JLAPP & 5,25 & 6 & 5,55 \\
\hline 3 & Leoni & 5,5 & 6 & 5,7 \\
\hline
\end{tabular}

Tabel 14 Nilai Total Kriteria Lead Time

\begin{tabular}{|l|l|l|l|l|}
\hline No & Nama & NCF & NSF & NT \\
\hline 1 & Supreme & 6 & 0 & 3,6 \\
\hline 2 & JLAPP & 5 & 0 & 3 \\
\hline 3 & Leoni & 5 & 0 & 3 \\
\hline
\end{tabular}

\subsection{Perhitungan Penentuan Ranking Vendor}

Setelah selesai pada tahap perhitungan nilai total, maka tahap selanjutnya adalah perhitungan penentuan ranking, vendor yang mendapat poin tertinggi akan mendapatkan peringkat 1 (pertama) sehingga dapat dikatakan sebagai vendor yang terbaik di antara vendor-vendor yang telah dilakukan penilaian. Dari ketiga kriteria yaitu kriteria kualitas, kriteria harga, dan kriteria lead time masingmasing kriteria memperoleh nilai persen yaitu 40\%, 30\% dan $30 \%$.

Tabel 15 Hasil Akhir Proses Profile Matching

\begin{tabular}{|c|c|c|c|c|c|}
\hline No & Nama & Nk & Nh & N $l$ & Hasil Akhir \\
\hline 1 & Supreme & 6 & 5,65 & 3,6 & $\mathbf{5 , 1 8}$ \\
\hline 2 & JLAPP & 6 & 5,55 & 3 & 4,97 \\
\hline 3 & Leoni & 6 & 5,7 & 3 & 5,01 \\
\hline
\end{tabular}

Pada tabel 15 dapat dilihat bahwa vendor supreme meraih peringkat pertama dengan mendapatkan hasil akhir dengan nilai 5,18. Kemudian vendor Leoni meraih peringkat kedua dengan hasil akhir sebesar 5,01 dan vendor JLAPP meraih peringkat terakhir dengan nilai hasil akhir sebesar 4,97.

\section{KESIMPULAN}

Setiap perusahaan perlu melakukan penilaian kinerja vendor. Penilaian kinerja dapat mengukur dan menilai vendor yang tetap memegang komitmen terhadap perusahaan. Penilaian kinerja dapat membantu mendukung keputusan dalam melakukan pemilihan vendor nantinya. Pemilihan vendor yang tepat dapat dilakukan dengan menentukan kriteria-kriteria yang telah ditetapkan dan kriteria yang diharapkan dapat meminimalkan resiko yang akan timbul. Berdasarkan penggunaa Metode Profil Matching, dapat ditentukan ranking vendor dari yang tertinggi hingga terendah. Vendor yang menempati peringkat pertama adalah vendor Supreme dengan nilai hasil akhir sebesar 5,18 dan vendor Leoni 5,01 dan vendor JLAPP 4,97. Hasil pemeringkatan ini menjadi bahan masukkan baik bagi perusahaan dalam menetukan vendor mana yang akan dijadikan sebagai mitra utama maupun bagi vendor sebagai bahan evaluasi guna meningkatkan kinerjanya sehingga dapat menjadi pilihan utama bagi perusahaan.

\section{REFERENSI}

Arini, D. 2015. Analisis Pemilihan Vendor Dengan Menggunkan Pendekatan Metode Fuzzy Topsis Di PT. Tripatra Engineers and Constructors. Jurnal Ilmiah Teknik IndustriI, 3(1), 53-58

Kurniawan, R., Hasibuan, S., \& Nugroho, R. E. 2017. Analisis Kriteria Dan Proses Seleksi Kontraktor Chemical Sektor Hulu Migas: Aplikasi Metode Delphi AHP. Jurnal Ilmiah Manajemen, VII(2), 252266

Latif, Lita Asyriati, dkk. 2018. Sistem Pendukung Keputusan Teori dan Implementasi. Yogyakarta: Deepublish

Mufid, A. (2014). Sistem Pendukung Keputusan Penilaian Proposal Kegiatan PNPM MPd Menggunakan Metode Profile Matching dan Analytic Hierarchy Process (AHP). Jurnal Sistem Informasi Bisnis, 1, 40-47.

Nisa, Khoirun dan Sutinah, Entin 2018. Profile Matching Untuk Sistem Pendukung Keputusan Pemilihan Vendor Maintenance Server dan Jaringan. Jurnal Informatika, 5(2): 262-269.

Permana, A. A. J. (2016). Sistem Pendukung Keputusan Penentuan Supplier Suku Cadang Mobil Pabrikan Eropa Dalam Konteks Interaksi Manusia Komputer. JANAPATI, 5(3), 142-148

Sutinah, Entin Sistem, Pendukung Keputusan Menggunakan Metode Profile Matching Dalam Pemilihan Salesman Terbaik, Jurnal Informatics for Educators and Professionals, Vol. 2, No. 1, Desember 2017, 29-42 